\title{
Orthodontic Management of a Patient with Cerebral Palsy: Six Years Follow-up
}

\author{
${ }^{1}$ Fidan Alakus Sabuncuoglu, ${ }^{2}$ Erkan Özcan
}

\begin{abstract}
Aim: Cerebral palsy $(\mathrm{CP})$ is a disorder that affects muscle tone, movement and motor skills. CP can also lead to other health issues, including vision, hearing and speech problems, as well as learning disabilities and dental problems. A case report describing the successful orthodontic treatment of a 10-year-old boy with the dyskinesia type of CP and severe malocclusion is presented.
\end{abstract}

Materials and methods: A 10-year and 2-month old boy was presented by his parents for orthodontic treatment, complaining of his unsatisfactory occlusion and poor chewing efficacy. An extraoral examination showed a convex profile. An intraoral examination showed the patient to be in mixed dentition with a class II molar relationship, $10 \mathrm{~mm}$ overjet and $4 \mathrm{~mm}$ overbite. In addition, his maxillary and mandibular arches were severely crowded. Cephalometric analysis indicated a severe skeletal class II discrepancy, which was confirmed by an ANB of $12^{\circ}$. The first phase of treatment involved the use of twin blocks with a headgear tube to attempt some growth modification and reduce the overjet. Once it was clear that the appliance was being well tolerated and the oral hygiene was satisfactory, the fixed appliance was used.

Results: Because of the good participation of the patient and his parents, orthodontic treatment was successful in the patient, achieving a normal overjet in combination with successful orofacial therapy.

Conclusion: As demonstrated in our case report, the success of the treatment was dependent on the cooperation of the patient and his parents. Furthermore, this case illustrates the importance of the treatment by a dental team in patients with CP.

Keywords: Cerebral palsy, Dyskinesia, Orthodontic treatment, Dental team.

How to cite this article: Sabuncuoglu FA, Özcan E. Orthodontic Management of a Patient with Cerebral Palsy: Six Years Followup. J Contemp Dent Pract 2014;15(4):491-495.

\section{Source of support: Nil}

Conflict of interest: None declared

\footnotetext{
${ }^{1}$ Orthodontist, ${ }^{2}$ Periodontologist

1,2Department of Orthodontics, Marasal Çakmak Military Hospital Dental Center, Turkey
}

Corresponding Author: Fidan Alakus Sabuncuoglu Orthodontist, Department of Orthodontics, Marasal Çakmak Military Hospital Dental Center, Turkey, e-mail: fidansabuncuoglu@yahoo.com.tr

\section{INTRODUCTION}

Cerebral palsy (CP) is a permanent, nonprogressive, neuromuscular disorder caused by damage to the immature brain. The severity of the brain lesion can vary greatly, but the prevalence of $\mathrm{CP}$ has remained reasonably constant at approximately 2 in 1000 live births by school age in industrialized nations. ${ }^{1}$ The incidence of $\mathrm{CP}$ is usually 0.15 to $0.3 \%$ of the general population (compared to a $3 \%$ incidence of mental retardation). Since, the etiology occurs during the developing years, $\mathrm{CP}$ is one of several developmental disabilities (DD). ${ }^{1}$

The muscles of the face and oral cavity play a role in facial growth and occlusal development. ${ }^{2}$ People with CP may present with physical and mental challenges that have implications for oral care. Malocclusion in people with CP usually involves more than just misaligned teeth - it is also a musculoskeletal problem. An open bite with protruding anterior teeth is common and is typically associated with tongue thrusting. The inability to close the lips because of an open bite also contributes to excessive drooling. The drooling of saliva, sometimes a major problem in these children, could be a manifestation of particularly poor orofacial muscle function, and it is possible that children with $\mathrm{CP}$ who have a habit of drooling may have increased malocclusion., ${ }^{3,4}$

The different types of $\mathrm{CP}$ are classified according to associated motor impairments: such as hemiplegia, diplegia, dyskinesia and quadriplegia. The following case report presents the successful treatment of a 10-year-old boy with the dyskinesia type of CP.

\section{CASE REPORT}

A 10-year and 2-month old boy was presented by his parents for orthodontic treatment, complaining of his unsatisfactory occlusion and poor chewing efficacy. The child was under medical treatment during his first year of life because of convulsive crises. He had always been cared for by his parents in all daily activities. The child has been followed up by a multidisciplinary team including a pediatrician, physiotherapist, psychologist and neurologist.

A physical examination at the time of referral showed vascular malformations in the right arm and right leg, especially in the ankle. 


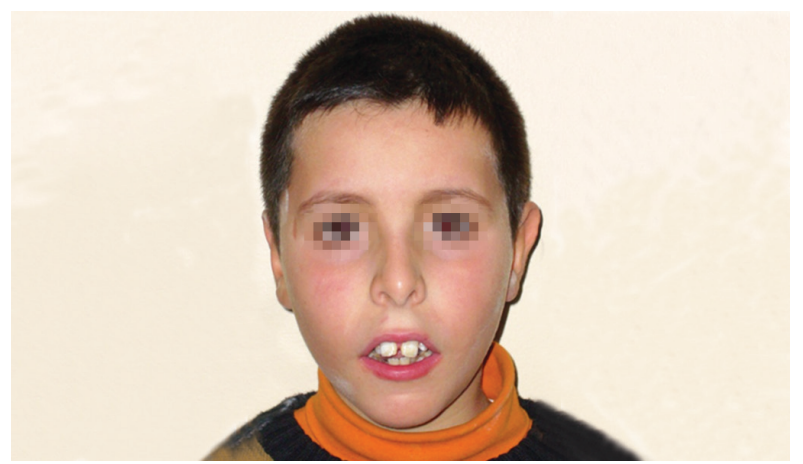

Fig. 1: Pre treatment extraoral view

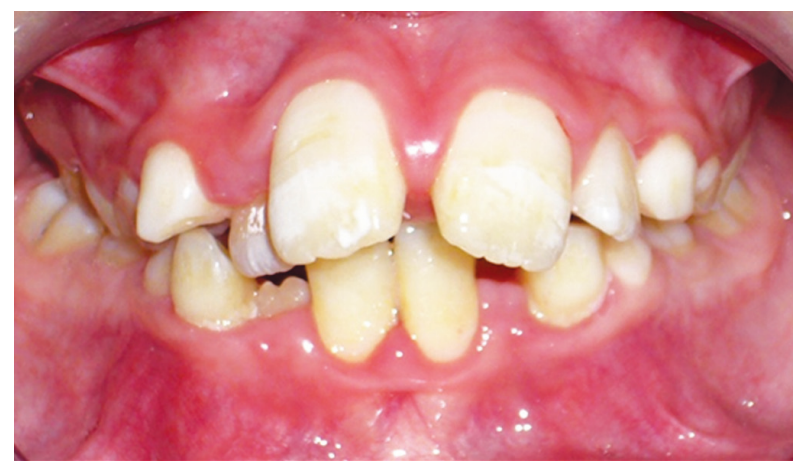

Fig. 2: Pre treatment intraoral view

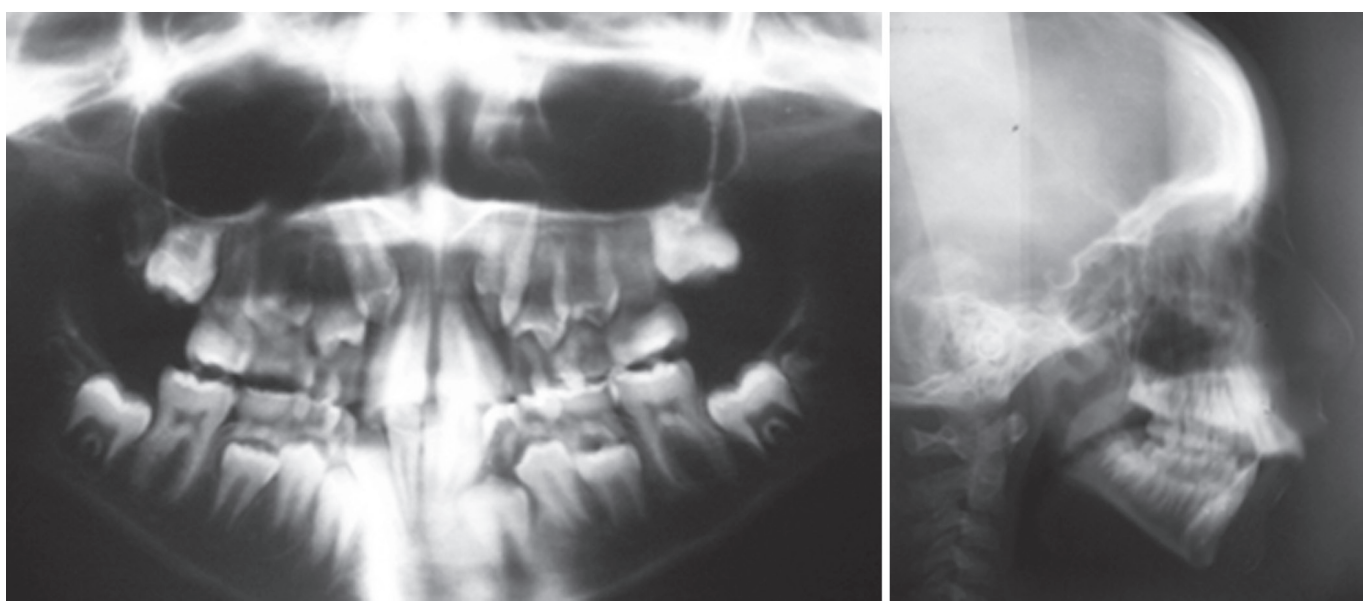

Figs 3A and B: (A) Pretreatment panoramic radiograph, (B) Pretreatment cephalometric radiograph

An extraoral examination showed a convex profile. An intraoral examination showed the patient to be in mixed dentition with a class II molar relationship, a $10 \mathrm{~mm}$ overjet and a $4 \mathrm{~mm}$ overbite. In addition, his maxillary and mandibular arches were severely crowded (Figs 1 and 2).

Cephalometric evaluation of the patient revealed a skeletal class II malocclusion with an ANB angle of $12^{\circ}$ and a $\mathrm{SN} / \mathrm{Go}-\mathrm{Gn}$ angle $53^{\circ}$. The patient had a convex profile and $\mathrm{S}-\mathrm{Go} / \mathrm{N}-\mathrm{Me}$ ratio was $50 \%$ and increase in the mandibular plane, emphasized the posterior rotation of the mandible, revealing that the patient had a long face. The upper incisors were proclined, while the lower incisors were retroclined (Table 1 and Fig. 3).

Treatment phase: Our aim was to achieve an esthetically acceptable and functional result, but not necessarily orthodontic perfection. The first phase of treatment involved the use of twin blocks with a headgear tube to attempt some growth modification and reduce the overjet. After 2 weeks, the patient's parents reported that the child had received the appliance well. The patient was periodically followed up to control and clean the appliances, apply topical fluoride, and instruct the parents on oral hygiene. The patient was extremely co-operative and the overjet reduced substantially within a period of 6 months.

Once it was clear that the appliance was being well tolerated and the oral hygiene was satisfactory, the fixed appliance was used. The maxillary and mandibular first premolar teeth were extracted to relieve crowding. Bands and brackets were placed using a 'straight wire' appliance and a NiTi archwire was placed. 0.014" NiTi and 0.016" $\mathrm{NiTi}$ archwires were attached for initial leveling. Following the leveling phase, $0.016^{\prime \prime} \times 0.022^{\prime \prime}$ archwires were placed

Table 1: Cephalometric analysis of case

\begin{tabular}{llll}
\hline Measurement & Normal & Pretreatment & $\begin{array}{c}\text { Post- } \\
\text { treatment }\end{array}$ \\
\hline SNA & $82^{\circ} \pm 2$ & $81^{\circ}$ & $80^{\circ}$ \\
SNB & $80^{\circ} \pm 2$ & $69^{\circ}$ & $74^{\circ}$ \\
ANB & +2 & $12^{\circ}$ & $6^{\circ}$ \\
NV-A & $0 \mathrm{~mm}$ & $0 \mathrm{~mm}$ & $0 \mathrm{~mm}$ \\
NV-Pog & $-4 /-6 \mathrm{~mm}$ & $-18 \mathrm{~mm}$ & $-8 \mathrm{~mm}$ \\
SN/Go-Gn & $32^{\circ}$ & $53^{\circ}$ & $40^{\circ}$ \\
N-Me & - & 141 & 136 \\
N-ANS & - & 59 & 57 \\
ANS-Me & - & 81 & 77 \\
Co-A & - & $83 \mathrm{~mm}$ & $81 \mathrm{~mm}$ \\
Co-Pog & - & $103 \mathrm{~mm}$ & $93 \mathrm{~mm}$ \\
S-Go/ N-Me & $62-65 \%$ & $50^{\circ}$ & $55^{\circ}$ \\
1/SN & $103^{\circ}$ & $110^{\circ}$ & $105^{\circ}$ \\
1-NA & $4 \mathrm{~mm}$ & $9 \mathrm{~mm}$ & $4 \mathrm{~mm}$ \\
1/NA & $22^{\circ}$ & $32^{\circ}$ & $25^{\circ}$ \\
1/Go-Gn & $93^{\circ}$ & $78^{\circ}$ & $85^{\circ}$ \\
1-NB & $4 \mathrm{~mm}$ & $3 \mathrm{~mm}$ & $4 \mathrm{~mm}$ \\
1/NB & $25^{\circ}$ & $20^{\circ}$ & $23^{\circ}$ \\
\hline
\end{tabular}




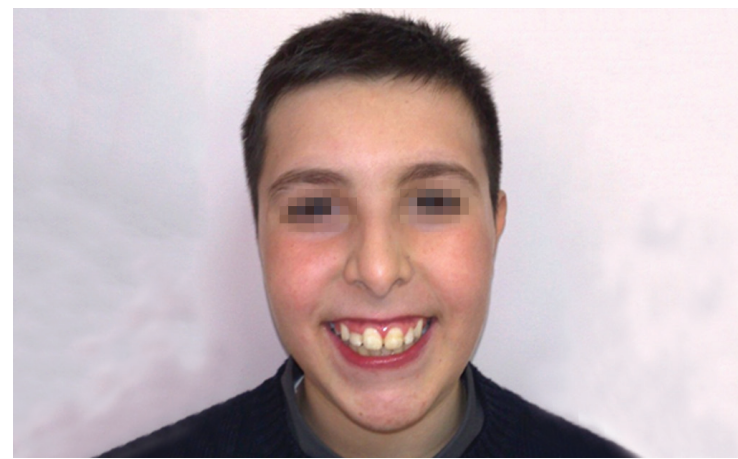

Fig. 4: Posttreatment extraoral view

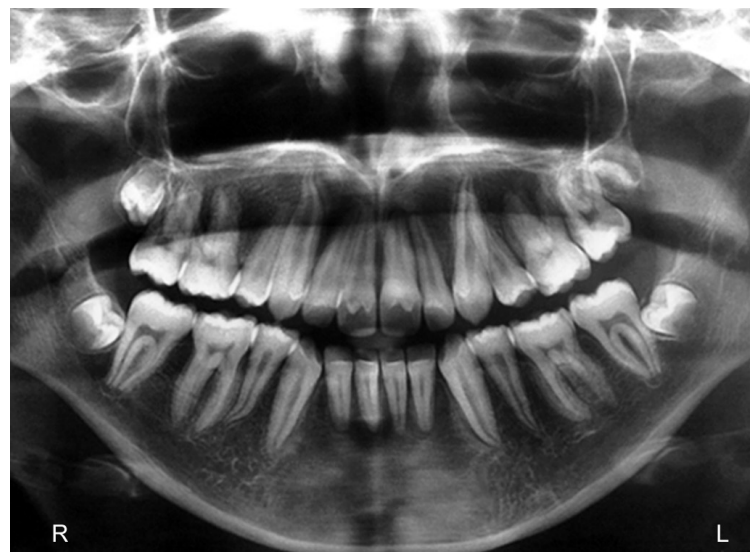

Figs $6 \mathrm{~A}$ and $\mathrm{B}:(\mathrm{A})$ Posttreatment panoramic radiograph,

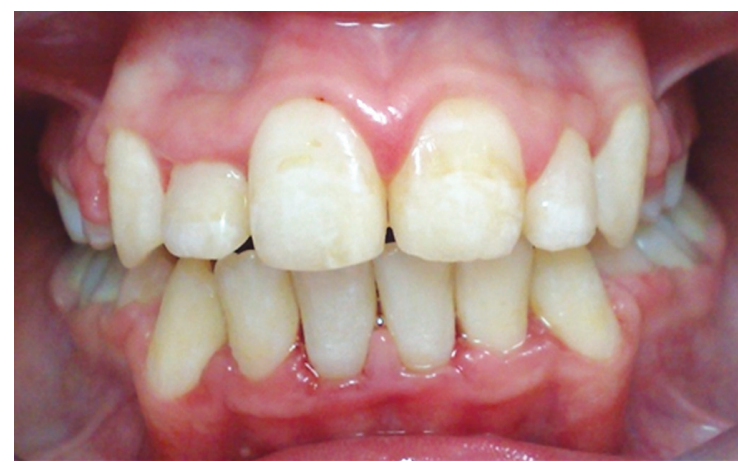

Fig. 5: Posttreatment intraoral view

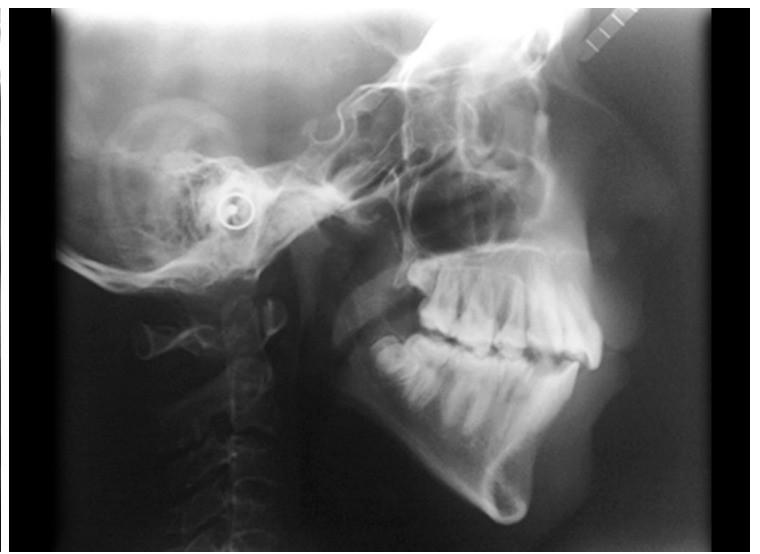

on the upper and lower teeth and final space closure was achieved using NiTi closing springs and class II elastics.

Immediately after the removal, essix retainers were placed. The patient was asked to wear them full time for 6 months and at night thereafter.

\section{RESULTS}

The final results showed acceptable aligned arches with the overjet reduced successfully and improved interdigitation in the buccal segments and orofacial therapy (Table 1, Figs 4 to 6 ). The child remains under continued intervention by a multidisciplinary team.

\section{CONCLUSION}

The provision of dental care to individuals with $\mathrm{CP}$ poses a particular challenge to dental practitioners. The limitations to treatment choices must be carefully explained to parents if inappropriate expectations are to be avoided. As demonstrated in our case report, the success of the treatment was dependent on the cooperation of the patient and his parents.

\section{DISCUSSION}

For centuries, society has found it difficult to deal with patients with special needs because of their physical, mental, social, sensory, neurologic and emotional problems. ${ }^{5-7}$ These difficulties are the result of the historical legacy and lack of information, which generate prejudices and lack of preparation on the part of society. The benefit of increased knowledge in the area of diagnosis and treatment for those with $\mathrm{CP}$ will allow orthodontists and their staff to be more comfortable and effective in delivering the best possible care. ${ }^{8,9}$

There is contradictory information in the literature regarding the incidence of oral diseases in patients with CP. According to Brown, ${ }^{10}$ these controversies are due to the failure of the criteria used to choose the population to be studied, as well as the absence of control groups.

Information on the incidence of dental decay in individuals with $\mathrm{CP}$ is conflicting, especially since many earlier studies utilized institutionalized subjects who had highly controlled diets. Most recent studies indicate that people with $\mathrm{CP}$ experience a somewhat higher degree of dental decay, primarily due to poor oral hygiene. ${ }^{11}$ Santos ${ }^{12}$ observed a high risk for dental caries in $\mathrm{CP}$ children. This poor oral hygiene is the direct result of the inability of many $\mathrm{CP}$ patients to physically cope with brushing and flossing activities. Many other factors contribute to the decay problem, including soft diet, enamel hypoplasia, mouth breathing, antidrooling drugs, and food retained in the mouth longer than usual due to dysphasia. ${ }^{9-11}$ However, no carious lesions were diagnosed in the patient described in the present case. This may be explained by the fact that the parents had received oral hygiene and diet instructions in a pediatric clinic 
when the child was very young and have always been very careful with the child's oral hygiene.

There is extensive documentation of an increased incidence of periodontal disease and gingivitis in the $\mathrm{CP}$ population. The incidence of periodontal disease has been estimated as 3 times higher than in the general population. Poor oral hygiene and gingival hyperplasia due to dilantin therapy are the major contributors to this problem. ${ }^{12,13}$ In this case, before orthodontic treatment patient received scaling, subgingival curettage to under control inflammation and during orthodontic treatment period professional dental care was performed at regular intervals.

A dramatic increase in the incidence of class II malocclusion is a common finding in people with $\mathrm{CP}$. Abnormal muscle and tongue movements are responsible for tongue thrust, which then creates an anterior open bite. Most of the class II malocclusions represent a skeletal problem, not merely the malalignment of teeth. The anterior open bite with protruding splayed anterior teeth, together with abnormal muscle movement and posture problems, are responsible for much of the trauma to anterior teeth seen in this population. This anterior trauma, with resultant tooth fractures and avulsions, is also a major problem for dental staff. Dry lips, due to mouth breathing, are also a common finding. ${ }^{14}$ In this case, the aim of first phase of treatment involved the use of twin blocks with a headgear tube was treatment myofunctional therapy and in the second phase, the occlusal correction was completed.

Bruxism is a common finding in persons with $\mathrm{CP}$, especially those most severely affected. An incidence of $58 \%$ in the institutionalized CP population has been reported. The effects of this bruxism are aggravated by hypoplasia, as previously cited. Although the bruxism seen in this population is much more clinically severe than the stress bruxism often seen in the general population, pulp exposures are rare. The severe wear seen in bruxism with many of these patients is apparent on the lingual cusps of the upper permanent molars and buccal cusps of the lower permanent molars, which leads to loss of vertical dimension and may contribute to problems in the temporomandibular joint. ${ }^{15,16}$ However, no bruxism that cause severe wear tooth was diagnosed in the patient described in the present case.

The main characteristics associated with the prevalence of malocclusion in patients with $\mathrm{CP}$ are musculoskeletal abnormalities, altered cranial-base relationships, pre-mature tooth eruptions and lip incompetence. Early, multidisciplinary treatment can help minimize the harmful effects of malocclusion and improve the quality of life of these patients, like in this case. ${ }^{13}$

No differences in the eruption times of primary or permanent teeth have been reported in individuals with $\mathrm{CP}$ when compared to the general population. ${ }^{13}$
If a general anesthetic is thought appropriate for dental treatment, then placement of an orthodontic appliance can be carried out at the same time as any necessary extractions or restorative or periodontal treatments. ${ }^{17}$ The risks of providing a general anesthetic are well described. The mortality rate in dental practice has not changed over the last 20 years. Between 1971 and 1975, there were 5.5 million general anesthetics provided for dental care and 26 deaths of children were reported. ${ }^{17}$ More recently, between 1986 and 1990, 1.4 million general anesthetics were given and 7 children died. The incidence of fatality in children undergoing dental procedures under a general anesthetic is therefore approximately 1:200,000. The general anesthetic procedure itself carries a significant degree of risk and Poswillo ${ }^{18}$ suggested strict guidelines if such a procedure is undertaken. In this case, general anesthetic is not thought during treatment, because of cooperation of the patient and his parents.

The aims of orthodontic treatment for patients with learning disability must be modified from achieving an 'ideal' result. Clinicians should aim for an esthetically acceptable and functional result, but not necessarily orthodontic perfection. This requires pragmatism and an ability to choose less conventional treatment plans at times. It is essential that visits are kept short and are not too stressful for either the patient or the operator. ${ }^{19}$

\section{REFERENCES}

1. Franklin DL, Luther F, Curzon ME. The prevalence of malocclusion in children with cerebral palsy. Eur J Orthod 1996 Dec;18(6):637-643.

2. Katz CR. Integrated approach to outpatient dental treatment of a patient with cerebral palsy: a case report. Spec Care Dentist 2012 Sep-Oct;32(5):210-217.

3. Davis MJ. Parotid salivary secretion and composition in cerebral palsy. J Dent Res 1979 Aug;58(8):1808.

4. Grzić R, Bakarcić D, Prpić I, Jokić NI, Sasso A, Kovac Z, Lajnert V. Dental health and dental care in children with cerebral palsy. Coll Antropol 2011 Sep;35(3):761-764.

5. Abanto J, Carvalho TS, Bönecker M, Ortega AO, Ciamponi AL, Raggio DP. Parental reports of the oral health-related quality of life of children with cerebral palsy. BMC Oral Health 2012 Jun $18 ; 12: 15$.

6. Wessels KE. Oral conditions in cerebral palsy. Dent Clinics of North America 1960;4:455-468.

7. Nunn JH, Murray JJ. The dental health of handicapped children in Newcastle and Northumberland. British Dent J 1987;162: 9-14.

8. Pope JEC, Curzon MEJ. The dental status of cerebral palsied children. Pediatric Dentistry 1991 May-Jun;13(3):156-162.

9. Rodrigues dos Santos MT, Masiero D, Novo NF, Simionato MR. Oral conditions in children with cerebral palsy. J Dent Child (Chic) 2003;70(1):40-46.

10. Moreira RN, Alcântara CE, Mota-Veloso I, Marinho SA, RamosJorge ML, Oliveira-Ferreira F. Does intellectual disability affect 
the development of dental caries in patients with cerebral palsy? Res Dev Disabil 2012 Sep-Oct;33(5):1503-1507.

11. Roberto LL, Machado MG, Resende VL, Castilho LS, Abreu MH. Factors associated with dental caries in the primary dentition of children with cerebral palsy. Braz Oral Res 2012 Sep-Oct; 26(5):471-477. Epub 2012 Aug 14.

12. Dos Santos MT, Masiero D, Simionato MR. Risk factors for dental caries in children with cerebral palsy. Spec Care Dentist 2002;22(3):103-107.

13. Kavanaugh J. The dental treatment of the cerebral palsied patient. J Dent Que 1982 Mar;82(19):47-52.

14. Gum SW. A roentgenographic cephalometric survey of the skeletal and dental patterns of the celepral palsied. Am J Orthodont 1962;48:66-67.
15. Oliveira CA, de Paula VA, Portela MB, Primo LS, Castro GF. Bruxism control in a child with cerebral palsy. ISRN Dent. 2011;2011:146915. doi: 10.5402/2011/146915. Epub 2010 Dec 1.

16. Zhu X, Zheng SG, Zheng Y, Fu KY, Zhou YS, Yu C. The related factors of bruxism in children. Zhonghua Kou Qiang Yi Xue Za Zhi 2009;44(1):15-18.

17. Murray JJ. General anaesthesia and children's dental health: present trends and future needs. Anaesth Pain Control Dent 1993 Fall;2(4):209-216.

18. Curl C, Boyle C. Sedation for patients with movement disorders. Dent Update 2012 Jan-Feb;39(1):45-48.

19. Becker A, Shapira J, Chaushu S. Orthodontic treatment for disabled children: motivation, expectation and satisfaction. Eur J Orthod 2000 Apr;22(2):151-158. 